\title{
A vegetação de canga no Quadrilátero Ferrífero, Minas Gerais: caracterização e contexto fitogeográfico
}

Canga vegetation in the Iron Quadrangle, Minas Gerais: characterization and phytogeographical context

\author{
Flávio Fonseca do Carmo ${ }^{1,2}$ \& Claudia Maria Jacobi ${ }^{1}$
}

\begin{abstract}
Resumo
A vegetação nas cangas (afloramentos ferruginosos) abriga dezenas de espécies raras, várias novidades taxonômicas e elevada diversidade alfa e beta. Utilizando um banco de dados constituído por 1.080 táxons de angiospermas, a vegetação associada às cangas no Quadrilátero Ferrífero foi caracterizada a partir dos elementos florísticos, das formas de crescimento e das fisionomias mais frequentes. Analisou-se a distribuição geográfica e os domínios fitogeográficos de 980 espécies. Ainda, com o objetivo de verificar se há distinção entre a vegetação das cangas em relação às de cinco áreas inseridas em sistemas rupestres de Minas Gerais e Bahia, analisou-se a similaridade a partir do número de espécies de 920 gêneros de angiospermas. Em comparação aos sistemas quartzíticos, principalmente os inseridos na Cadeia do Espinhaço, pode-se distinguir a vegetação das cangas pela maior influência de elementos florísticos do domínio Atlântico, maior frequência de sinúsias formadas por árvores e arbustos, riqueza elevada de espécies de gêneros como Solanum e Cattleya e pouca representatividade físionômica de alguns gêneros típicos dos campos rupestres. Essa distinção parece correlacionar-se com a localização geográfica do Quadrilátero e com as características geomorfológicas e mineralógicas das cangas. Palavras-chave: sistemas rupestres, Cadeia do Espinhaço, vegetação metalófila, geossistema ferruginoso, afloramentos ferruginosos.

Abstract

The vegetation in cangas (ironstone outcrops) houses dozens of rare species, several taxonomic novelties, and high alpha and beta diversity. Using a database consisting of 1080 angiosperm taxa, the vegetation associated with cangas in the Iron Quadrangle was characterized by its floristic elements, growth forms, and most frequent physiognomies. We analyzed the geographic distribution and the phytogeographic dominions of the 980 species. Also, in order to verify distinctions between canga vegetation in relation to five areas embedded in rupestral systems of Minas Gerais and Bahia, we analyzed the similarity of 920 angiosperm genera based in the species number. Compared to other rocky systems, especially those within the Espinhaço Range, canga vegetation is distinguished by the greater influence of floristic elements from the Atlantic dominion, greater frequency of arboreal and shrubby sinusiae, high abundance of genera like Solanum and Cattleya, and little physiognomic representation of some typically 'campos rupestres' genera. This distinction appears to be correlated with the geographic location of the Iron Quadrangle as well as the mineral and geomorphological characteristics of cangas. Key words: rupestral systems, Espinhaço Range, metalophilous vegetation, ferruginous geosystem, ironstone outcrops.
\end{abstract}

\section{Introdução}

Os sistemas rochosos constituem geoformas muito antigas, geralmente sustentando uma flora relictual edaficamente controlada e caracterizada pelo elevado número de endemismos (Bussel \& James 1997; Giulietti et al. 1997; Kruckeberg 2004; Vincent \& Meguro
2008). Scarano (2007), ao discutir o panorama da produção do conhecimento sobre a vegetação associada aos afloramentos rochosos, destaca a necessidade urgente de acelerar estudos nesses ambientes, em especial nas áreas de cangas. Estas áreas constituem um dos sistemas menos conhecidos, onde a principal causa de perda

\footnotetext{
${ }^{1}$ Universidade Federal de Minas Gerais - UFMG, Inst. Ciências Biológicas, Av. Antônio Carlos 6627, Pampulha, Belo Horizonte, MG.

${ }^{2}$ Autor para correspondência: carmo.flaviof@gmail.com
} 
de habitat e degradação deve-se à abertura de dezenas de cavas de extração de minério de ferro (Carmo et al. 2012).

As cangas são afloramentos formados há milhões de anos resultante do intemperismo de rochas ferríferas subjacentes - tais como os itabiritos e diamictitos ferruginosos - e posterior enriquecimento de ferro, resultando em couraças que podem atingir dezenas de metros de espessura e se estender por milhares de hectares (Dorr II 1969; Schobbenhaus \& Coelho 1986; Castro 2008). A vegetação associada às cangas abriga dezenas de espécies raras (sensu Giulietti et al. 2009), várias destas novas para a ciência, e elevada diversidade alfa e beta (Viana \& Lombardi 2007; Jacobi \& Carmo 2008a; Jacobi \& Carmo 2012). Apesar disto, estas áreas possuem representatividade insignificante dentro do sistema nacional de unidades de conservação de proteção integral (Jacobi et al. 2011).

As couraças ferruginosas localizam-se predominantemente no estado de Minas Gerais, principalmente no Quadrilátero Ferrífero e ao longo da vertente leste da Cadeia do Espinhaço. Outras localidades relevantes são a Serra de Carajás (Pará), a Morraria do Urucum (Mato Grosso do Sul) e a região de Caetité (Bahia) (Carmo et al. 2012). Com freqüência, as cangas distribuem-se insularmente nas porções mais altas do relevo, recobrindo jazidas de minério de ferro e constituindo extensos platôs interconectados por vales e escarpas (Dorr II 1969; Carmo et al. 2011). Fundamentados nas peculiaridades geomorfológicas, hidrogeológicas, paleoambientais e na singularidade das comunidades de plantas e invertebrados associados às formações ferríferas e as cangas, Jacobi et al. (no prelo) sugeriram agrupar estas áreas metalíferas sob o termo geossistema ferruginoso. Foi adotado o conceito de geossistema (Bertrand 1972), e não o de ecossistema, porque além de incluir o conceito de complexos rupestres de Semir (1991), abrange ainda as interações entre os processos climatológicos, geomorfológicos, biológicos e antrópicos como estruturadores de uma paisagem dinâmica (Rodrigues 2001).

Vários termos foram propostos para denominar a vegetação associada às cangas, como campos ferruginosos (Rizzini 1979), savana metalófila (Porto \& Silva 1989), vegetação metalófila (Silva 1992), campos rupestres ferruginosos (Mourão \& Stehmann 2007; Viana \& Lombardi 2007) e vegetação de bancada laterítica (Silva \& Tozzi 2011). Até hoje a nomenclatura permanece incerta e imprecisa, e este cenário demanda uma sistematização do conhecimento gerado para subsidiar uma caracterização mais precisa da vegetação. Da perspectiva da conservação do patrimônio biológico, esta ação é estratégica, pois o refinamento na localização e na caracterização da biodiversidade brasileira é fundamental para que os tomadores de decisão priorizem objetivamente os alvos de conservação das futuras áreas protegidas (Dinerstein et al. 2005).

Este trabalho tem como objetivos: realizar uma classificação mais precisa da vegetação associada às cangas no Quadrilátero Ferrífero a partir da análise dos elementos florísticos, de suas formas de crescimento e das fisionomias mais frequentes; e investigar se há distinção florística e fitogeográfica entre essa vegetação em relação à vegetação de cinco áreas inseridas em sistemas rupestres em Minas Gerais e Bahia.

\section{Material e Métodos}

No Quadrilátero Ferrífero, região central de Minas Gerais, compõem o geossistema ferruginoso rochas com alta concentração de ferro, constituintes das Formações Cauê e Gandarela (Grupo Itabira, Supergrupo Minas), e as cangas que as recobrem. O termo canga, na verdade uma corruptela de tapanhoacanga, foi introduzido na nomenclatura geológica por Wilhelm Ludwig von Eschwege no inicio do século XIX, juntamente com a definição do termo itabirito, a partir de descrições de amostras coletadas em localidades-tipo inseridas no Quadrilátero Ferrífero (Renger 2005). Essa localidade abrangia originalmente cerca de 185 $\mathrm{km}^{2}$ de cangas (Baltazar 2005).

Um banco de dados foi constituído a partir de estudos florísticos exclusivos de cangas no Quadrilátero Ferrífero situadas entre 900 e 1.850 $\mathrm{m}$, predominando os afloramentos localizados acima de $1.400 \mathrm{~m}$ (Jacobi et al. 2007; Mourão \& Stehmann 2007; Viana \& Lombardi 2007; Jacobi \& Carmo 2012). Foram incluídas as espécies afins de outros táxons, variedades e espécies novas para a ciência e excluídas as exóticas e invasoras, resultando em 1.080 táxons de angiospermas, distribuídos em 102 famílias e 418 gêneros. 
Caracterização da vegetação sobre cangas

A vegetação foi caracterizada de acordo com a descrição das principais sinúsias e as formas de crescimento das espécies, composto pela proporção de árvores, arbustos, subarbustos, ervas, palmeiras, parasitas e trepadeiras, adaptado de Viana \& Lombardi (2007).

\section{Contexto fitogeográfico}

Foram excluídas as espécies não descritas e os táxons identificados apenas em nível genérico, resultando em 980 espécies. Para cada uma dessas, foram determinados a distribuição geográfica, a partir da ocorrência por estado, e os domínios fitogeográficos seguindo Jacobi \& Carmo (2012) e a Lista de Espécies da Flora do Brasil (2012).

Foram comparadas também as relações florísticas entre a vegetação que ocorre nas cangas e em cinco sistemas quartzíticos, dos quais quatro estão inseridos na Cadeia do Espinhaço (MG/BA), onde predominam os campos rupestres (sensu Giulietti et al. 1997), e um na Serra de São José (Tab. 1), município de Tiradentes (MG), no limite com a Zona da Mata mineira. Com exceção do presente banco de dados de cangas, composto por espécies exclusivamente inventariadas em afloramentos, todos os outros consideraram também as espécies inventariadas nas fisionomias de cerrado, caatinga e floresta estacional semidecidual. A área total de coleta nas cangas foi o somatório da superfície de 18 afloramentos cuja distância média linear entre eles foi de $39 \mathrm{~km}$.
A análise de classificação baseou-se em uma matriz de similaridade em nível genérico. Para as seis localidades foi encontrado um total de 920 gêneros de angiospermas. Cada gênero foi quantificado pelo número de espécies (incluindo espécies afins, variedades e espécies novas para a ciência) extraídos das listas florísticas. Foi necessária atualização nomenclatural, seguindo a Lista de Espécies da Flora do Brasil (2012), uma vez que as floras foram publicadas ao longo dos últimos 25 anos, trazendo diferentes delimitações no nível genérico. Entre as atualizações estão as de espécies de Vernonia Schreb. atualmente estabelecidas, por exemplo, em Lepidaploa (Cass.) Cass., Lessingianthus H. Rob. e Vernonanthura H. Ros.; Panicum L. em Apocloa Zuloaga \& Morrone e Ocellochloa Zuelloaga \& Morrone; Maxillaria Ruiz \& Pav. em Christensonella Szlach., Mytnik, Górniak \& Smiszek .

Realizou-se, com auxílio do programa PAST (Hammer et al. 2001), uma análise de agrupamentos por médias não ponderadas (UPGMA) e o índice de similaridade de Bray-Curtis. A robustez dos grupos foi verificada através de 5.000 repetições aleatórias onde, para cada raiz de um agrupamento, foi informada a porcentagem de vezes que incluiu um mesmo conjunto de objetos.

Para cada uma das localidades foram identificados os 25 gêneros com maior riqueza específica e foram construídos diagramas ternários para visualizar o posicionamento destes gêneros ao longo de um gradiente, ou setores fitogeográficos. $\mathrm{O}$ posicionamento de um gênero no diagrama foi

Tabela 1 - Localização e caracterização das seis áreas contendo sistemas rochosos que integraram o banco de dados do presente estudo.

Table 1 - Location and characterization of the six areas on rock systems that composed the data set in this study.

\begin{tabular}{|c|c|c|c|c|c|c|}
\hline \multirow{2}{*}{ Local } & \multirow{2}{*}{$\begin{array}{c}\text { Altitude } \\
\text { máxima } \\
\text { (m) }\end{array}$} & \multirow{2}{*}{$\begin{array}{l}\text { Área } \\
\left(\mathbf{k m}^{2}\right)\end{array}$} & \multicolumn{3}{|c|}{ Angiospermas $\left(n^{\circ}\right)$} & \multirow{2}{*}{$\begin{array}{c}\text { Domínio } \\
\text { fitogeográfico }\end{array}$} \\
\hline & & & Famílias & Gêneros & Espécies & \\
\hline 1. Catolés, Cadeia do Espinhaço, BA (Zappi et al. 2003) & 2.033 & 667 & 123 & 584 & 1.669 & Caatinga \\
\hline 2. Pico das Almas, Cadeia do Espinhaço, BA (Stannard 1995) & 1.958 & 170 & 110 & 396 & 994 & Caatinga \\
\hline 3. Grão-Mogol, Cadeia do Espinhaço, MG (Pirani et al. 2003) & 1.250 & 100 & 111 & 452 & 1.078 & Cerrado \\
\hline 4. Serra do Cipó, Cadeia do Espinhaço, MG (Giulietti et al. 1987) & 1.500 & 200 & 122 & 508 & 1.555 & Cerrado \\
\hline 5. Quadrilátero Ferrífero, MG & $1.880^{*}$ & $6^{*}$ & 102 & 418 & 1.080 & $\begin{array}{c}\text { Mata }^{\#} \\
\text { Atlântica }\end{array}$ \\
\hline 6. Serra de São José, MG (Alves \& Kolbek, 2009) & 1.430 & 25 & 108 & 428 & 1.077 & $\begin{array}{c}\text { Mata } \\
\text { Atlântica }\end{array}$ \\
\hline
\end{tabular}

*para ocorrência de cangas - * for cangas occurences

\# Spósito \& Stehmann (2006); Fundação SOS Mata Atlântica (2011) 
estabelecido a partir de três coordenadas geradas pela soma da proporção relativa da sua frequência encontrada nas duas localidades inseridas no Espinhaço baiano (domínio da Caatinga); duas no Espinhaço mineiro (domínio do Cerrado); e duas no setor centro-sul mineiro (domínio da Mata Atlântica). Dessa forma, quanto mais próximo um gênero estiver de um vértice, maior a influência fitogeográfica do domínio representado. A frequência total foi definida como a soma do número de vezes que as espécies ocorreram nas localidades.

\section{Resultados e Discussão}

\section{Caracterização da vegetação} sobre cangas

As ervas (37\%) constituem a forma de crescimento mais frequente entre as espécies, seguida pelos arbustos $(21 \%)$, subarbustos $(20 \%)$, árvores $(11 \%)$ e trepadeiras $(10 \%)$. Parasitas e palmeiras somam 1\% (Fig. 1). As espécies herbáceas foram mais frequentes entre as famílias Poaceae (99), Orchidaceae (79), Cyperaceae (43), Bromeliaceae (28) e Eriocaulaceae (27). Em geral, o componente herbáceo não forma um estrato contínuo ao longo das couraças, praticamente não ocorrendo nos setores onde o elevado grau de cimentação da canga determina um substrato bastante compacto e conhecido como lajeado. Nesses setores, as espécies rupícolas predominantes são as de crescimento clonal, destacando-se as ilhas de Trilepis lhotzkiana Nees (Cyperaceae), Acianthera teres (Lindl.) Borba (Orchidaceae) e Vellozia spp. Vand (Velloziaceae).

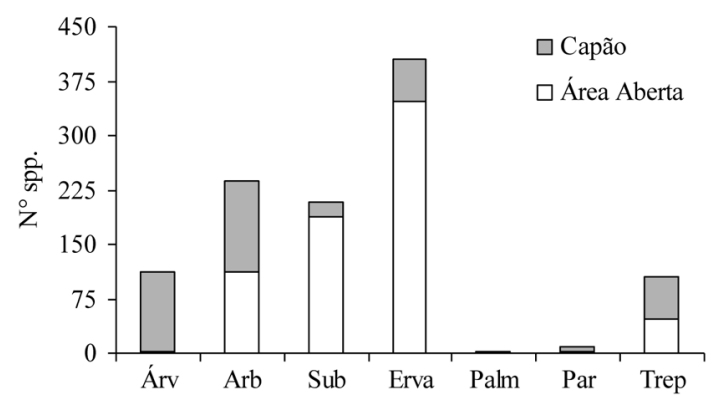

Figura 1 - Formas de crescimento da vegetação em cangas do Quadrilátero Ferrífero, MG. Árv: árvore; Arb. Arbusto; Sub: subarbusto; Palm: palmeira; Par: parasita; Trep: trepadeira

Figure 1 - Growth forms of the vegetation associated with Iron Quadrangle cangas, MG. Árv: tree; Arb. shrub; Sub: sub-shrub; Palm: palm; Par: parasite; Trep: lianas and vines; Capão: forest islands; Área aberta: open area.
As espécies arbustivas mais frequentes pertencem a Asteraceae (28), Solanaceae e Melastomataceae (27 cada), Verbenaceae (20) e Malpighiaceae (16). Asteraceae e Rubiaceae caracterizaram-se pela maior riqueza de espécies subarbustivas, com 93 e 23 respectivamente. As trepadeiras foram mais frequentes entre as Apocynaceae (31), Asteraceae (15) e Fabaceae (10). Lorantaceae e Santalaceae apresentaram ao total seis espécies hemiparasitas e Apodanthaceae e Convolvulaceae somaram duas holoparasitas. Entre as árvores, destacam-se pela riqueza específica as famílias Myrtaceae (29), Melastomataceae (15) e Lauraceae (14). Pelo mesmo critério, destacam-se os gêneros Myrcia DC. (15), Miconia Ruiz \& Pavon (14) e Ocotea Aubl.(8).

A contribuição relativa de algumas formas de crescimento pode variar bastante tanto entre as cangas quanto ao longo da superfície de uma mesma couraça. As espécies arbóreas, arbustivas e as trepadeiras, por exemplo, ocorrem concentradas em sinúsias associadas a vestíbulos de cavernas (clarabóias), a grandes depressões e fendas no substrato que, dependendo da canga, distribuemse de forma agregada ou aleatória no espaço. Estas sinúsias podem assumir desde um aspecto semelhante ao escrube descrito por Caiafa \& Silva (2005) até a fisionomia e porte de um capão de mata, com algumas árvores atingindo $15 \mathrm{~m}$ de altura como as Fabaceae Abarema obovata (Benth.) Barneby \& J.W. Grimes e Copaifera langsdorffii Desf. e a Myrtaceae Calyptranthes clusiifolia O. Berg. Esses ambientes representam em média de $10 \%$ a $30 \%$ da área total de uma couraça (Carmo \& Jacobi 2012), raramente somando mais de 50\% da superfície de uma canga. Entre os gêneros mais numerosos contendo espécies arbustivas e frequentemente associados a essas sinúsias estão Solanum L. (13), Leandra Raddi (8), Symplocos Jacq. (7) e Psychotria L. (6). Entre as epífitas, predominam os gêneros Tillandsia L. (6) e Peperomia Ruiz \& Pav. (4) e entre as trepadeiras, predominam Mikania Willd.(14), Passiflora L.(6), Dioscorea L. e Serjania Mill (4 cada).

Quando na couraça ocorre elevada quantidade de fissuras e fendas, os gêneros mais característicos da vegetação graminóide e com a maior riqueza específica são Paspalum L. e Panicum (13 cada), Rhynchospora (11), Andropogon e Axonopus P. Beauve (8 cada). Nesses setores, a estrutura horizontal da vegetação é geralmente dominada pelos arbustos (Rizzini 1979; Viana \& Lombardi 2007; Jacobi et al. 
2008b) que se desenvolvem mesmo na ausência de solo na superfície das couraças. Entre eles, os gêneros com a maior riqueza específica foram Stachytarpheta Vahl.(7), Byrsonima Rich ex Kunth. e Lippia L. (6) Baccharis L., Lychnophora Mart. e Mimosa L. (4 cada). Provavelmente, o predomínio dos arbustos na fisionomia geral também está relacionado a uma das características mais singulares das cangas, a presença de milhares de micro e mesocavidades (centimétricas) que contribuem, juntamente com as centenas de macrocavernas já inventariadas, para a elevada heterogeneidade espacial subsuperficial (Carmo \& Jacobi 2012).

Onde a umidade permanece elevada durante todo o ano, como vestíbulos de cavernas, canais de drenagem, lagoas e brejos, os gêneros mais abundantes e habitualmente encontrados são Paepalanthus Mart. (16), Xyris L. (15), Habenaria Willd. (8) e Eleocharis R.Br.(5). As lagoas e brejos estão restritos a poucas cangas no Quadrilátero Ferrífero, abrangendo uma área total estimada menor que 300 ha. Constituem os únicos ambientes brejosos conhecidos no Brasil e desenvolvidos nos geossistemas ferruginosos que podem atingir cotas altitudinais superiores a $1.300 \mathrm{~m}$ (Carmo \& Jacobi 2012).

Todas essas características geomorfológicas e topográficas, gerando diversos tipos de habitats, contribuem para a elevada variabilidade entre as proporções relativas de cada forma de crescimento e, portanto, para a variabilidade fisionômica entre e dentro das cangas. Essa relação entre a heterogeneidade espacial e a variação na estrutura e na composição da vegetação em sistemas rochosos é bem estabelecida na literatura brasileira (Ribeiro \& Medina 2002; Caiafa \& Silva 2005; Conceição \& Pirani 2005). O que distingue as cangas da maioria dos sistemas rochosos conhecidos é sua heterogeneidade espacial subsuperficial que favorece uma relevante parcela da biomassa vegetal, representada pelo sistema radicular, a desenvolver-se pelos espaços das cavidades subterrâneas e pelas fendas, formando estruturas excepcionais como rizotemas e tufos suspensos no seu interior (Ferreira 2005; Carmo \& Jacobi 2012).

\section{Contexto fitogeográfico}

De acordo com a distribuição geográfica, as espécies inventariadas nas cangas foram inseridas em cinco grupos: Grupo 1) espécies restritas ao estado de Minas Gerais (17\%), a maioria exclusivamente associada aos ambientes rupestres da Cadeia do Espinhaço, e com cerca de 60 espécies endêmicas do Quadrilátero Ferrífero (Jacobi \& Carmo, 2012); Grupo 2) espécies que ocorreram nos estados de MG e BA (3\%), predominantemente na Cadeia do Espinhaço; Grupo 3) espécies restritas à região Sudeste (8\%); Grupo 4) espécies com ampla distribuição, porém ainda exclusivas do Brasil (37\%); Grupo 5) espécies não exclusivas do Brasil (35\%). Incluem-se neste último as espécies subespontâneas, tais como Emilia fosbergii Nicolson, Hypoxis decumbens L. e Solanum americanum Mill.

$\mathrm{Na}$ Cadeia do Espinhaço, diversos autores identificaram cinco padrões de distribuição geográfica para as espécies de campos rupestres: espécies endêmicas do Espinhaço; espécies disjuntas entre o Espinhaço e áreas rupestres em Goiás; disjunção entre o Espinhaço e a restinga; disjunção entre o Espinhaço e os tepuis do norte da América do Sul; e espécies de ampla distribuição geográfica (Giulietti et al. 1987; Harley 1995; Rapini et al. 2008). Dois desses padrões foram nitidamente observados nas cangas: espécies endêmicas da Cadeia do Espinhaço e espécies amplamente distribuídas. Os outros três padrões não foram claramente estabelecidos para as couraças ferruginosas. Apenas duas das 980 espécies inventariadas também ocorrem em áreas disjuntas nas restingas do leste do Brasil (seguindo Alves et al. 2007), 23 espécies em áreas disjuntas em Goiás, e três espécies ocorrem também nos tepuis (seguindo Harley 1995; Alves et al. 2007).

Os domínios fitogeográficos com maior influência na vegetação associada às cangas foram a Mata Atlântica e o Cerrado. Do total de espécies, $18 \%$ foram exclusivas do domínio Atlântico. No componente arbustivo-arbóreo são freqüentes os elementos florísticos característicos dos topos de montanhas do leste do país, como Calyptranthes clusiifolia O. Berg, Eremanthus incanus (Less.) Less., Geonoma schottiana Mart e Symplocos celastrinea Mart. Elementos característicos das matas nebulares (sensu Valente et al., 2011) do domínio Atlântico são igualmente habituais, como Clethra scabra Pers., Drimys brasiliensis Miers, Guapira opposita (Vell.) Reiz, Psychotria stachyoides Benth. e Weinmannia paulliniifolia Pohl ex Ser. (Oliveira-Filho \& Fontes 2000; Pereira et al. 2006). No componente herbáceo das áreas abertas, destaca-se na fisionomia a espécie endêmica das cangas do Quadrilátero Paspalum brachytrichum Hack.

As espécies exclusivas do domínio Cerrado totalizaram $16 \%$, a maioria ocorrendo na Cadeia do Espinhaço mineiro e nos estados de Goiás e 
São Paulo. As espécies desse grupo estão associadas frequentemente ao componente herbáceo-arbustivo das áreas abertas, como Aspilia subpetiolata Baker, Calea rotundifolia (Less.) Baker, Galianthe angustifolia (Cham. \& Schltdl.) E.L. Cabral e Hyptis rotundifolia Benth. Entre os gêneros com mais espécies estão Cattleya Lindl., Stachytarpheta Vahl. e Vellozia.

As espécies que ocorrem tanto no Cerrado quanto na Mata Atlântica somam 20\% do total e predominam em duas sinúsias: a arbustivo-arbórea e a campestre. Leandra aurea (Cham.) Cogn. e Vochysia emarginata (Vahl) Poir. integram o primeiro componente. Chromolaena decumbens Gardner e Sporobolus reflexus Boechat \& Longhi Wagner inserem-se no segundo componente da vegetação.

As espécies que ocorrem nos domínios Mata Atlântica, Cerrado e Caatinga somaram 12\% do total. Integram esse grupo Chaptalia integerrima (Vell.) Burkart, Diodella radula (Willd. ex Roem. \& Schult.) Delprete, Matelea pedalis (E.Fourn.) Fontella \& E.A.Schwarz, Pfaffia jubata Mart e Symplocos oblongifolia Casar. As espécies que se distribuem entre as várias combinações fitogeográficas somam $34 \%$ do total (Tab. 2) e, entre elas, estão Anthurium scandens (Aubl.) Engl., Baccharis retusa DC., Bulbostylis capillaris (L.) C.B. Clarke, Centropogon cornutus (L.) Druce, Pyrostegia venusta (Ker Gawl.) Miers e Tripodanthus acutifolius (Ruiz \& Pav.) Tiegh.

Nas cangas, uma relevante fração das espécies consideradas de ampla distribuição no Brasil (Grupo 4, 37\% do total) tem na realidade seus limites de ocorrência concentrados no leste do país, o que claramente relaciona-se com a inserção geográfica do Quadrilátero Ferrífero, no contato da Mata Atlântica com o Cerrado e recebendo uma forte influência de elementos florísticos característicos desses domínios fitogeográficos.

O problema da escala na definição de padrões fitogeográficos, quando a informação limita-se a unidades políticas, já foi apontado por Alves \& Kolbek (2010). Entre os reflexos diretos desse viés estão a superestimativa da amplitude das áreas de ocorrência e a falta de distinção entre os ambientes ou habitats, principalmente quando o foco do estudo são as plantas exclusivas a certos tipos de substratos ou limitadas a elevadas cotas altitudinais. Nessas situações, as populações de espécies geralmente distribuem-se em áreas restritas que podem, por sua vez, estar insularmente distribuídas por enormes extensões. Assim, um refinamento da informação sobre os locais e os habitats das
Tabela 2 - Domínios fitogeográficos das espécies inventariadas nas cangas do Quadrilátero Ferrífero, MG. MA: Mata Attântica; CE: Cerrado; CA: Caatinga; AM: Amazônia; PM: Pampa; PT: Pantanal.

Table 2 - Phytogeographic dominions of the species inventoried in the Iron Quadrangle cangas. MA: Atlantic Rainforest; CE: Cerrado; CA: Caatinga; AM: Amazon; PM: Pampa; PT: Pantanal.

\begin{tabular}{lcc}
\hline Domínio Fitogeográfico & $\mathbf{n}^{\circ}$ spp. & $\%$ \\
MA & 180 & 18,5 \\
CE & 159 & 16,2 \\
CE; MA & 198 & 20,2 \\
CA; CE; MA & 119 & 12,1 \\
AM; CA; CE; MA & 89 & 9,1 \\
CA; CE & 39 & 4,0 \\
AM; CE; MA & 29 & 3,0 \\
CE; MA; PM & 17 & 1,7 \\
AM; CA; CE & 16 & 1,6 \\
AM; CE & 8 & 0,8 \\
outros & 30 & 3,0 \\
todos & 93 & 9,5 \\
desconhecido & 3 & 0,3 \\
\hline Total & 980 & 100 \\
\hline
\end{tabular}

espécies inventariadas nas cangas, consideradas no presente trabalho como de ampla distribuição, poderá contribuir para uma melhor delimitação da sua área de ocorrência. Ao mesmo tempo, poderá contribuir para uma distinção mais evidente entre um grupo de espécies restrito aos sistemas rupestres (elementos florísticos de formações azonais), um grupo exclusivo das formações zonais e um grupo de espécies que pode ocorrer em ambos e, portanto, constituído por elementos florísticos generalistas.

De acordo com a análise de similaridade, um agrupamento foi gerado pelas quatro áreas inseridas na Cadeia do Espinhaço, ou província fitogeográfica do Espinhaço (Giulietti et al. 1997): Pico das Almas + Catolés agrupando-se a Grão-Mogol e em seguida à Serra do Cipó. As cangas juntamente com a Serra de São José formaram um grupo distinto. Em todos os casos, valores de bootstrap entre 77 e 95 indicaram forte coesão entre os agrupamentos formados com similaridades entre $55 \%$ e $65 \%$ (Fig. 2).

Os 25 gêneros com a maior riqueza abrigaram entre 24 e $33 \%$ do total de espécies de cada uma das seis localidades e resultaram em um conjunto de 64 gêneros (Tab. 3). Xyris foi o gênero mais 


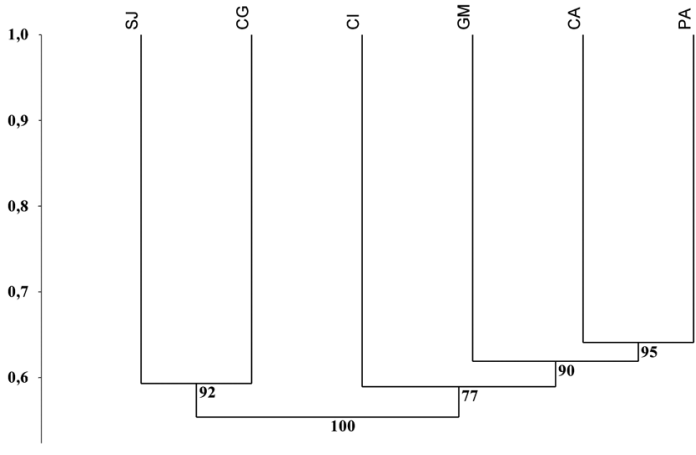

Figura 2 - Dendrograma de similaridade baseado no número de espécies de 920 gêneros de angiospermas (UPGMA; coeficiente de similaridade Bray-Curtis: cc 0,884). Bootstrap: 5000 repetições. SJ: Serra de São José; CG: Cangas; CI: Serra do Cipó; GM: GrãoMogol; CA: Catolés; PA: Pico das Almas.

Figure 2 - Similarity dendrogram based on the species number of 920 genera of angiosperms (UPGMA; Bray-Curtis index : cc 0.884). Bootstrap: 5000 repetitions. SJ: Serra de São José; CG: Cangas; CI: Serra do Cipó; GM: Grão-Mogol; CA: Catolés; PA: Pico das Almas.

frequente (139), seguido por Paepalanthus (128), Hyptis Jacq. (95), Chamaecrista Moench. (94), Microlicia D. Don. (93), Miconia Ruiz \& Pav. (86), Vellozia (84), Rhynchospora Vahl. (79), Baccharis (75) e Myrcia (75). Apenas quatro gêneros não ocorreram em todas as localidades. Agrianthus Mart. ex DC. ocorreu em Catolés e Pico das Almas, sendo endêmico da Bahia (Ferreira 2012) e predominando nos sistemas rupestres da Chapada Diamantina (Stannard 1995). Philodendron Schott., por outro lado, é ausente naquelas duas áreas. Eriope Humb \& Bonpl. ex Benth não foi amostrado para a S. São José e Siphocampylus Pohl. não ocorreu em Grão-Mogol.

Xyris foi o gênero com a maior riqueza nas localidades da Serra do Cipó (44) e em Pico das Almas (31). Hyptis foi o gênero com a maior riqueza em Catolés (33) e na Serra de São José (19) e Chamaecrista (22) em Grão-Mogol. Nas cangas, o maior número de espécies correspondeu ao gênero Solanum (19), representando a única localidade cujo gênero mais abundante não é característico da vegetação rupestre. Este fato relaciona-se ao elevado número de capões que favorece condições ambientais adequadas para as espécies ecotonais de Solanum (Mourão \& Stehmann 2007; Jacobi \& Carmo 2008a), especialmente quando ocorrem em cotas altitudinais acima de $1.000 \mathrm{~m}$ (Valente et al. 2011).
Gêneros com centros de diversidade na Cadeia do Espinhaço, tais como Chamaecrista, Hyptis e Syngonanthus Ruhland. (Harley 1996; Costa et al. 2008; Rando \& Pirani 2011) ou frequentes como Croton L. e Utricularia L. (Harley 1995; Rapini et al. 2008) figuram entre os 25 gêneros com a maior riqueza específica nas localidades inseridas em sistemas quartzíticos, mas não entre os 25 encontrados nas cangas do Quadrilátero. Outros gêneros freqüentes nos campos rupestres como Camarea A. St.-Hill e Drosera L. (Mamede 1990; Ferrero \& Mello-Silva 2011) ainda não foram amostrados nas couraças ferruginosas do Quadrilátero, embora estejam presentes nas outras cinco localidades (Tab. 1) e também em áreas brejosas desenvolvidas em matriz quartzítica ou filítica localizadas a poucas centenas de metros das cangas inventariadas. Esse padrão pode correlacionar-se com a constituição mineralógica das cangas, basicamente caracterizada pelas elevadas concentrações de minerais metálicos, notadamente o ferro (Silva 1992; Schaefer et al. 2008; Vincent \& Meguro 2008).

Outra situação que distingue a vegetação das cangas é a pouca influência de elementos florísticos de Eriocaulaceae e Xyridaceae na fisionomia ou aspecto estrutural campestre (Viana \& Lombardi 2007; Jacobi \& Carmo 2008a, b; Echternacht et al. 2012) quando comparado aos sistemas quartzíticos localizados no Espinhaço e na Serra de São José, onde essas sempre-vivas se destacam no estrato herbáceo (Giulietti \& Hensold 1990; Harley 1995; Costa et al. 2008; Alves \& Kolbek 2009). Provavelmente, a ausência de solos arenosos e/ ou a menor abrangência de ambientes brejosos reduzem a disponibilidade de habitat adequado ao estabelecimento daquelas famílias nas cangas.

No nível específico, vários levantamentos florísticos destacaram a elevada diversidade beta entre as áreas inventariadas no Espinhaço, principalmente entre as porções baiana e mineira, devido a uma possível barreira migratória representada por uma disjunção de $300 \mathrm{~km}$ entre as duas porções (Azevedo \& van den Berg 2007; Rapini et al. 2008). No presente estudo, a diversidade beta medida a partir das diferenças de riqueza dos gêneros foi relativamente menos pronunciada, agrupando as quatro áreas inseridas na província fitogeográfica do Espinhaço e segregando-as das cangas e da Serra de São José, apesar das distâncias entre a Serra do Cipó e o Quadrilátero e entre a Serra do Cipó e a Serra de São José serem inferiores a $90 \mathrm{~km}$ e $190 \mathrm{~km}$, respectivamente. Os diagramas ternários 


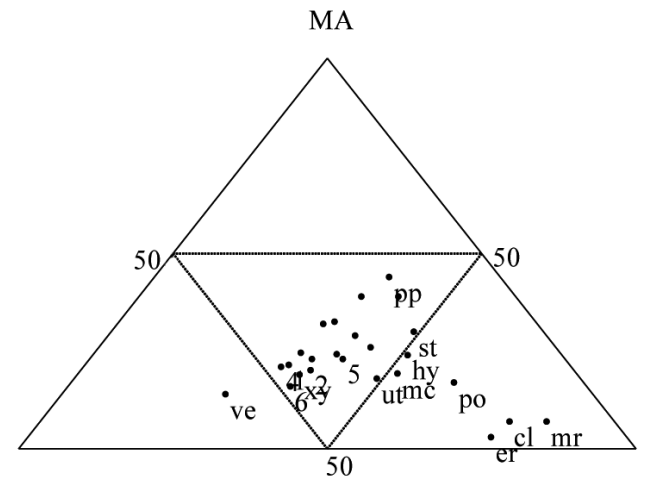

CE

\section{Catolés}

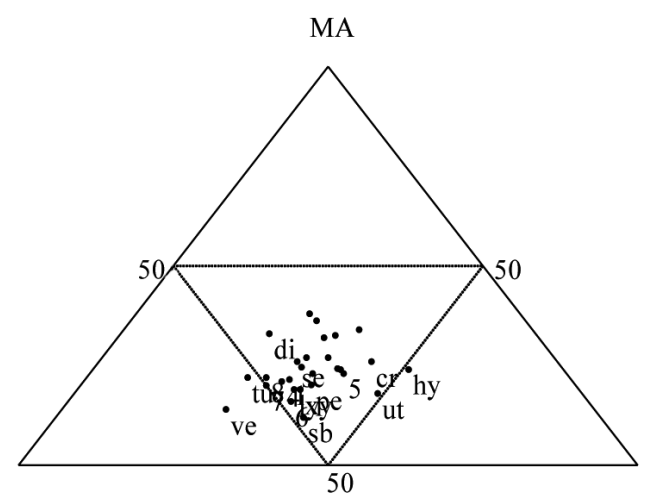

CE

CA

Grão-Mogol

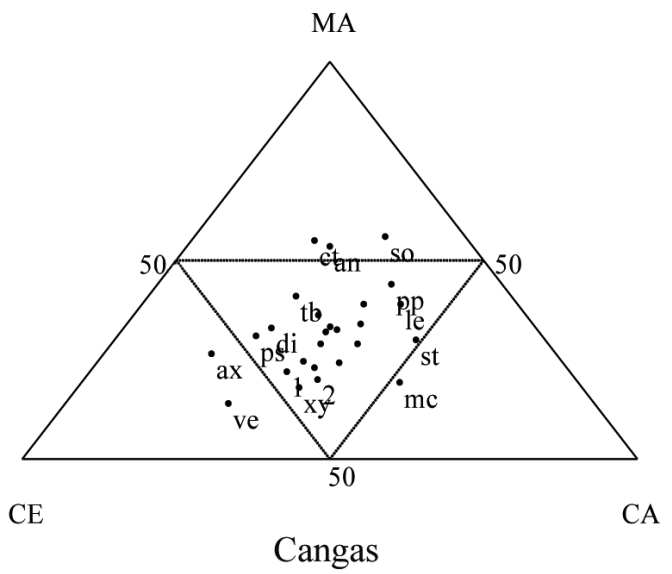

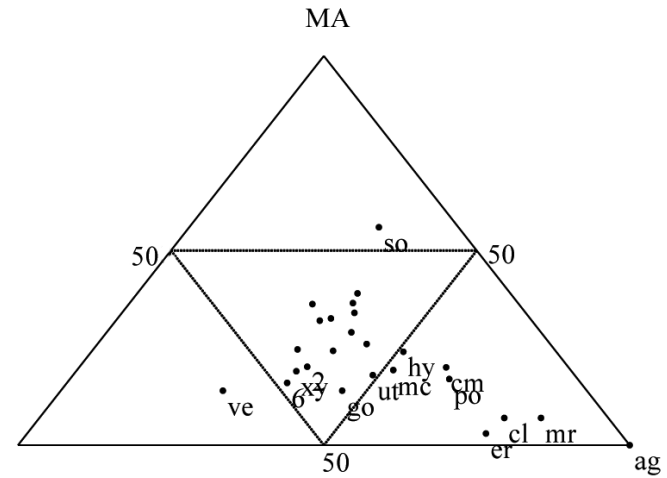

CE

Pico das Almas

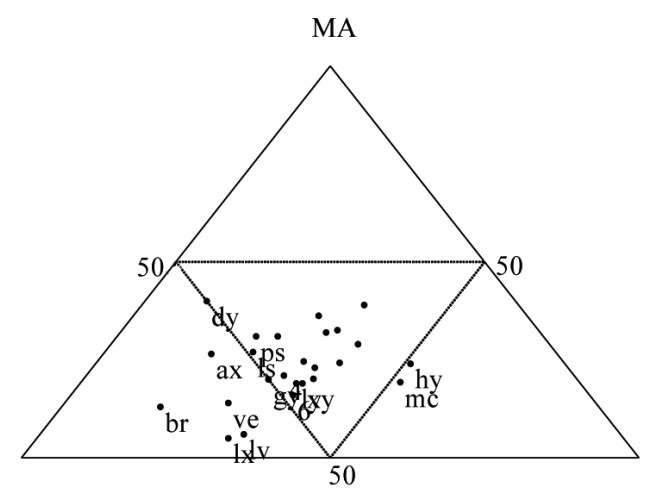

CE

CA

Serra do Cipó

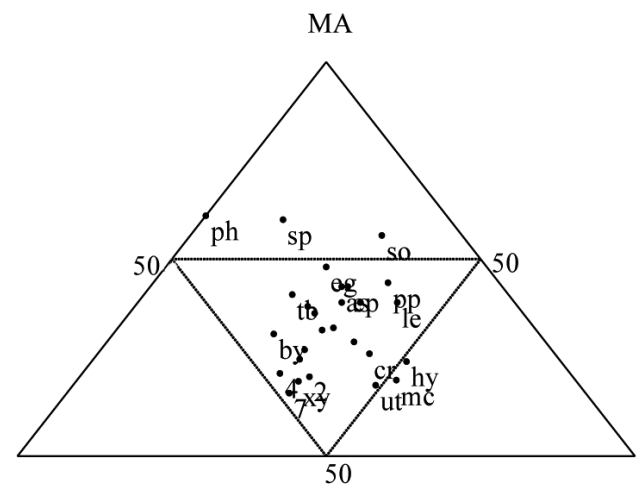

CE

Serra de São José

Figura 3 - Diagramas ternários obtidos a partir da frequência dos 25 gêneros com maior riqueza em cada uma das seis áreas investigadas. MA: setor Mata Atlântica; CE: setor Cerrado; CA: setor Caatinga. Consultar a Tabela 3 para a identificação dos códigos.

Figure 3 - Ternary diagrams obtained from the 25 most abundant genera in each area. MA: Atlantic Rainforest; CE: Cerrado; CA: Caatinga. For codes consult Table 3. 
Tabela 3 - Os 25 gêneros de angiospermas com maior número de espécies (cinza) em cada localidade (ver Tabela 1), ordenados a partir dos valores nas cangas do Quadrilátero Ferrífero, MG. Cod.: códigos da Figura 3.

Table 3 - The 25 genera with most species number (gray) in each locality (see table 1), ranked by the values found in Iron Quadrangle cangas. Cod.: codes for Figure 3.

\begin{tabular}{|c|c|c|c|c|c|c|c|}
\hline \multirow{3}{*}{ Gênero } & \multirow{3}{*}{ Cod. } & \multirow{2}{*}{\multicolumn{2}{|c|}{$\begin{array}{c}\text { Mata Atlântica } \\
\text { Setor Centro-Sul }\end{array}$}} & \multirow{2}{*}{\multicolumn{2}{|c|}{$\begin{array}{c}\text { Cerrado } \\
\text { Espinhaço MG }\end{array}$}} & \multirow{2}{*}{\multicolumn{2}{|c|}{$\begin{array}{c}\text { Caatinga } \\
\text { Espinhaço BA }\end{array}$}} \\
\hline & & & & & & & \\
\hline & & Cangas & S.S.José & S. Cipó & G. Mogol & P. Almas & Catolés \\
\hline Solanum L. (Solanaceae) & so & 19 & 11 & 1 & 6 & 7 & 10 \\
\hline Baccharis L. (Asteraceae) & & 18 & 11 & 15 & 4 & 14 & 13 \\
\hline Paepalanthus Mart. (Eriocaulaceae) & 2 & 16 & 10 & 41 & 14 & 15 & 32 \\
\hline Myrcia DC. (Myrtaceae) & & 16 & 8 & 16 & 10 & 10 & 15 \\
\hline Mikania Willd. (Asteraceae) & & 16 & 3 & 16 & 8 & 8 & 18 \\
\hline Xyris L. (Xyridaceae) & xy & 15 & 11 & 44 & 18 & 31 & 20 \\
\hline Miconia Ruiz \& Pavon (Melastomataceae) & & 14 & 14 & 15 & 13 & 16 & 14 \\
\hline Paspalum L. (Poaceae) & ps & 13 & 5 & 22 & 5 & 5 & 8 \\
\hline Panicum L. (Poaceae) & & 13 & 4 & 5 & 9 & 14 & 5 \\
\hline Rhynchospora Vahl. (Cyperaceae) & & 11 & 18 & 15 & 12 & 14 & 9 \\
\hline Lippia L. (Verbenaceae) & & 10 & 5 & 18 & 9 & 4 & 20 \\
\hline Microlicia D.Don. (Melastomataceae) & $\mathrm{mc}$ & 9 & 9 & 21 & 6 & 17 & 31 \\
\hline Polygala L. (Polygalaceae) & & 9 & 8 & 20 & 9 & 9 & 14 \\
\hline Tibouchina Aubl. (Melastomataceae) & tb & 9 & 11 & 12 & 5 & 3 & 9 \\
\hline Ditassa R.Br. (Apocynaceae) & di & 9 & 6 & 9 & 11 & 3 & 8 \\
\hline Ocotea Aubl. (Lauraceae) & & 9 & 2 & 10 & 4 & 5 & 8 \\
\hline Vellozia Vand. (Velloziaceae) & ve & 8 & 4 & 36 & 14 & 9 & 13 \\
\hline Habenaria Willd. (Orchidaceae) & & 8 & 8 & 13 & 4 & 11 & 11 \\
\hline Mimosa L. (Fabaceae) & & 8 & 3 & 12 & 11 & 7 & 11 \\
\hline Leandra Raddi (Melastomataceae) & le & 8 & 10 & 7 & 2 & 6 & 13 \\
\hline Peperomia Ruiz \& Pav. (Piperaceae) & $\mathrm{pp}$ & 8 & 9 & 4 & 3 & 3 & 12 \\
\hline Stachytarpheta Vahl. (Verbenaceae) & st & 8 & 3 & 4 & 4 & 4 & 14 \\
\hline Chromolaena DC. (Asteraceae) & & 8 & 4 & 11 & 1 & 4 & 8 \\
\hline Axonopus P.Beauve (Poaceae) & $\mathrm{ax}$ & 8 & 1 & 16 & 3 & 2 & 4 \\
\hline Andropogon L. (Poaceae) & an & 8 & 5 & 3 & 3 & 2 & 4 \\
\hline Cattleya Lindl. (Orchidaceae) & ct & 8 & 3 & 3 & 3 & 2 & 3 \\
\hline Chamaecrista Moench. (Fabaceae) & 6 & 7 & 8 & 23 & 22 & 7 & 27 \\
\hline Epidendrum L. (Orchidaceae) & ep & 7 & 10 & 7 & 3 & 5 & 8 \\
\hline Dyckia Schult. f. (Bromeliaceae) & dy & 7 & 5 & 14 & 1 & 2 & 1 \\
\hline Croton L. (Euphorbiaceae) & $\mathrm{cr}$ & 6 & 11 & 9 & 11 & 10 & 19 \\
\hline Eugenia L. (Myrtaceae) & 5 & 6 & 5 & 6 & 11 & 4 & 15 \\
\hline Byrsonima Rich ex Kunth. (Malpighiaceae) & & 6 & 7 & 13 & 5 & 6 & 5 \\
\hline Tillandsia L. (Bromeliaceae) & & 6 & 7 & 5 & 7 & 4 & 6 \\
\hline Psychotria L. (Rubiaceae) & & 6 & 3 & 5 & 7 & 5 & 7 \\
\hline Lessingianthus H.Rob. (Asteraceae) & ls & 6 & 3 & 13 & 3 & 2 & 6 \\
\hline
\end{tabular}




\begin{tabular}{|c|c|c|c|c|c|c|c|}
\hline \multirow{3}{*}{ Gênero } & \multirow{3}{*}{ Cod. } & \multirow{2}{*}{\multicolumn{2}{|c|}{$\begin{array}{c}\text { Mata Atlântica } \\
\text { Setor Centro-Sul }\end{array}$}} & \multirow{2}{*}{\multicolumn{2}{|c|}{$\begin{array}{c}\text { Cerrado } \\
\text { Espinhaço MG }\end{array}$}} & \multirow{2}{*}{\multicolumn{2}{|c|}{$\frac{\text { Caatinga }}{\text { Espinhaço BA }}$}} \\
\hline & & & & & & & \\
\hline & & Cangas & S.S.José & S. Cipó & G. Mogol & P. Almas & Catolés \\
\hline Cuphea P. Browne (Lythraceae) & & 5 & 7 & 11 & 7 & 5 & 10 \\
\hline $\begin{array}{l}\text { Banisteriopsis C.B.Rob. ex Small } \\
\text { (Malpighiaceae) }\end{array}$ & 7 & 5 & 3 & 11 & 8 & 4 & 8 \\
\hline Mandevilla Lindl. (Apocynaceae) & & 5 & 9 & 5 & 5 & 5 & 7 \\
\hline Senna Mill. (Fabaceae) & se & 5 & 3 & 6 & 7 & 2 & 8 \\
\hline Eleocharis R.Br. (Cyperaceae) & & 5 & 3 & 3 & 3 & 7 & 1 \\
\hline Hyptis Jacq. (Lamiaceae) & hy & 4 & 19 & 16 & 8 & 15 & 33 \\
\hline Lychnophora Mart. (Asteraceae) & ly & 4 & 5 & 13 & 7 & 6 & 10 \\
\hline Gaylussacia Kunth. (Ericaceae) & gy & 4 & 5 & 17 & 5 & 5 & 8 \\
\hline Erythroxylum P.Browne (Erythroxylaceae) & 8 & 4 & 5 & 7 & 13 & 6 & 6 \\
\hline Heteropterys (Malpighiaceae) & & 4 & 4 & 5 & 7 & 3 & 10 \\
\hline Barbacenia Vand. (Velloziaceae) & ba & 3 & 2 & 23 & 4 & 2 & 4 \\
\hline Lagenocarpus Nees (Cyperaceae) & & 3 & 6 & 9 & 1 & 7 & 5 \\
\hline Turnera L. (Turneraceae) & tu & 3 & 3 & 5 & 9 & 3 & 4 \\
\hline Aspilia Thouars (Asteraceae) & as & 3 & 7 & 4 & 2 & 4 & 3 \\
\hline Syngonanthus Ruhland. (Eriocaulaceae) & sy & 2 & 10 & 19 & 8 & 5 & 13 \\
\hline Phoradendron Nutt. (Santalaceae) & po & 2 & 6 & 4 & 6 & 12 & 17 \\
\hline Cambessedesia DC. (Melastomataceae) & $\mathrm{cm}$ & 2 & 3 & 3 & 2 & 7 & 8 \\
\hline Sebastiania Spreng. (Euphorbiaceae) & $\mathrm{sb}$ & 2 & 1 & 5 & 7 & 5 & 5 \\
\hline Eryngium L. (Apiaceae) & eg & 2 & 7 & 3 & 2 & 3 & 2 \\
\hline Siphocampylus Pohl. (Campanulaceae) & $\mathrm{sp}$ & 2 & 7 & 4 & 0 & 1 & 1 \\
\hline Utricularia L. (Lentibulariaceae) & ut & 1 & 9 & 10 & 8 & 13 & 13 \\
\hline Calliandra Benth. (Fabaceae) & $\mathrm{cl}$ & 1 & 2 & 3 & 4 & 7 & 25 \\
\hline Leiothrix Ruhland (Eriocaulaceae) & lx & 1 & 1 & 19 & 5 & 5 & 7 \\
\hline Gomphrena L. (Amaranthaceae) & go & 1 & 4 & 10 & 4 & 8 & 8 \\
\hline Lavoisiera DC. (Melastomataceae) & lv & 1 & 1 & 17 & 3 & 4 & 7 \\
\hline Eriope Humb \& Bonpl. ex Benth. (Lamiaceae) & er & 1 & 0 & 4 & 3 & 9 & 15 \\
\hline Marcetia DC. (Melastomataceae) & $\mathrm{mr}$ & 1 & 1 & 1 & 2 & 7 & 16 \\
\hline Philodendron Schott. (Araceae) & $\mathrm{ph}$ & 1 & 7 & 3 & 2 & 0 & 0 \\
\hline Agrianthus Mart. ex DC. (Asteraceae) & ag & 0 & 0 & 0 & 0 & 7 & 8 \\
\hline
\end{tabular}

construídos a partir da frequência dos 25 gêneros com maior riqueza de cada uma das áreas podem auxiliar nessa análise (Fig. 3).

A nuvem de pontos no centro dos diagramas corresponde aos gêneros que obtiveram equivalência nas proporções relativas (entre 25\% a 39\%) de frequência, independente do domínio fitogeográfico. A priori, a frequência desses gêneros relaciona-se mais com a ocorrência de ambientes adequados como, por exemplo, os capões e as áreas brejosas, fornecendo condições favoráveis ao estabelecimento de espécies de Cuphea P. Browne, Eleocharis, Eugenia L., Habenaria, Miconia, Mikania, Myrcia, Ocotea, Oxypetalum, Passiflora, Psychotria, Rhynchospora e Tillandsia (Giulietti et al. 1987; Harley 1995; Meguro et al. 1996; Ritter \& Waechter 2004; Carmo \& Jacobi 2012). Os gêneros Baccharis, Chromolaena DC., Lagenocarpus Nees, Mandevilla Lindl. 
e Panicum formam um grupo caracterizado pela elevada representatividade nos sistemas rupestres, campestres e savânicos do centro-leste do Brasil (Giulietti et al. 1987; Harley 1995; Pirani et al. 2003; Rapini et al. 2008; Viana \& Filgueiras 2008; Heiden et al. 2010) e, portanto, também obtiveram equivalência nas frequências entre as localidades. Todos esses gêneros estão representados nos diagramas apenas pelos seus pontos correspondentes.

Para alguns casos, o posicionamento do gênero no diagrama pode estar diretamente correlacionado à influência de elementos florísticos da matriz circundante. Por exemplo, gêneros muito diversos no Domínio Atlântico como Leandra, Peperomia, Philodendron, Solanum e Tibouchina Aubl. (OliveiraFilho \& Fontes 2000; Sakuragui 2000; Monteiro \& Guimarães 2008; Goldenberg et al. 2012) posicionaram-se no setor Mata Atlântica ou próximos dele. A elevada riqueza de Axonopus P.Beauve na Serra do Cipó deve-se à inserção dessa área no Domínio Cerrado, onde o gênero é especialmente abundante (Viana \& Filgueiras, 2008). O posicionamento dos gêneros Chamaecrista, Gomphrena L., Lessingianthus, Mimosa e Paspalum próximos aos setores Cerrado ou Caatinga relaciona-se à riqueza específica dos mesmos tanto na vegetação associada aos sistemas rupestres quanto nas fisionomias savânicas do centro-leste do Brasil (Giulietti et al. 1997; Simon \& Proença 2000; Dematteis \& Angulo 2010; Rando \& Pirani 2011).

Por outro lado, centros de diversidade representados principalmente pela Cadeia do Espinhaço estão relacionados ao posicionamento de gêneros como Barbacenia Vand., Dyckia Schult.f., Lavoisiera DC., Leiothrix Ruhland, Vellozia e Turnera L. no setor Cerrado (Giulietti \& Forero 1990; Giulietti \& Hensold 1990; Giulietti et al. 1997; Rapini et al. 2008; Versieux et al. 2008; Arbo \& Giulietti 2009). Da mesma forma, no setor da Caatinga, centros de diversidade estão relacionados ao posicionamento de Agrianthus, Calliandra Benth., Cambessedesia DC., Eriope, Hyptis, Marcetia DC. e Microlicia (Harley 1996; Romero 2003; Rapini et al. 2008). O posicionamento de Stachytarpheta sofreu influência do elevado número de espécies encontradas nas cangas (oito) e por isso não foi inserido totalmente no setor da Caatinga, um dos principais centros de endemismo do gênero (Atkins 2005), que concentrou $49 \%$ da frequência total observada.

As condições climáticas favoráveis, associadas à latitude ou à altitude, podem contribuir para o posicionamento de alguns gêneros como, por exemplo, Andropogon L. no setor Mata Atlântica. Garcia et al. (2009) comentam que temperaturas médias anuais entre $10-20^{\circ} \mathrm{C}$ e médias entre $5-15^{\circ} \mathrm{C}$ para o inverno são condições adequadas para a tribo Andropogoneae. Estas condições são semelhantes às encontradas no Quadrilátero e na região da Serra de S. José, especialmente nas altitudes acima de 1.200 m (Oliveira-Filho et al. 2005; ALMG 2012).

Estudos sobre a similaridade florística e fitogeografia que incluíram as localidades onde predominam os sistemas rupestres da Cadeia do Espinhaço e do Quadrilátero citaram entre os principais determinantes das comunidades vegetais a disponibilidade de habitat, a influência fitogeográfica e geoedáfica (Azevedo \& van den Berg 2007; Dutra et al. 2008; Viana \& Filgueiras 2008; Borges et al. 2010; Abreu et al. 2011).

A distinção das cangas entre as áreas localizadas na Cadeia do Espinhaço pode indicar, além de uma maior influência florística do Domínio Atlântico, o fator determinístico do substrato. Para a vegetação metalófila em geral (sensu Whiting et al. 2002), a questão geoedáfica constitui o principal fator estruturador das comunidades (Kruckeberg 2004). Gibson et al. (2010) demonstraram alta correlação entre raridade e endemismo na flora associada às formações ferríferas na Austrália, identificando-as como hotspots para a diversidade de plantas. No presente estudo, esse fator pode ser especialmente determinante para alguns grupos. Cattleya, por exemplo, foi o gênero com o maior número de espécies entre as Orchidaceae inventariadas nas cangas, sendo um terço das espécies endêmicas do Quadrilátero e algumas espécies, mesmo não restritas, concentrando suas populações principalmente nas couraças ferruginosas (Mota et al. 2012). O Quadrilátero pode ser considerado um hotspot (sensu Gibson et al. 2010) também para Bromeliaceae, onde as espécies endêmicas da região atingem um terço do total inventariado nas cangas (Versieux 2011, 2012) e para Convolvulaceae, com $26 \%$ das espécies restritas a localidade (Simão-Bianchini 2012).

$O$ fator geoedáfico parece não ter sido predominante para o posicionamento da Serra de São José. Nesta área, em comparação com os outros sistemas quartzíticos, ocorreu considerável similaridade entre a abundância de alguns gêneros típicos dos campos rupestres (Tab. 3) mas, por outro lado, houve entre os 25 gêneros com a maior riqueza alguns que apareceram apenas na Serra de São José, 
como Eryngium, Philodendron e Siphocampylus. Entre esses, várias espécies ocorrem apenas no domínio Atlântico, mas aparentemente não são restritas a este. Então, a distinção da Serra de São José parece relacionar-se mais com a influência florística devido a sua proximidade com a Zona da Mata mineira, fator provavelmente responsável pela sua segregação do agrupamento formado pelas áreas localizadas na Cadeia do Espinhaço e pelo seu agrupamento com as cangas.

A constituição mineralógica, a heterogeneidade espacial, a restrição geográfica e a vulnerabilidade distinguem as cangas dos outros sistemas rochosos brasileiros (Carmo \& Jacobi 2012). Em comparação com os sistemas quartzíticos, principalmente os inseridos na Cadeia do Espinhaço, pode-se fazer uma distinção da vegetação das cangas, sustentada pela maior influência de elementos florísticos do domínio Atlântico, elevada frequência de sinúsias formadas por árvores e arbustos; riqueza singular de gêneros como Solanum, Andropogon e Cattleya e a pouca influência de elementos de alguns gêneros típicos dos campos rupestres na fisionomia campestre das couraças ferruginosas.

\section{Agradecimentos}

À Fundação de Amparo à Pesquisa do Estado de Minas Gerais (FAPEMIG), ao Conselho Nacional de Desenvolvimento Científico e Tecnológico ( $\mathrm{CNPq})$ e ao US Fish and Wildlife Service, os financiamentos de projetos em cangas. Ao CNPq, as bolsas concedidas a FFC (doutorado) e $\mathrm{CMJ}$ (PQ 2). Aos taxonomistas, a valiosa colaboração para a elaboração das listas florísticas. Aos revisores do trabalho, as contribuições.

\section{Referências}

Abreu, N.L.; Neto, L.M. \& Konno, T.U.P. 2011. Orchidaceae das Serras Negra e do Funil, Rio Preto, Minas Gerais, e similaridade florística entre formações campestres e florestais do Brasil. Acta Botanica Brasilica 25: 58-70.

ALMG - Assembléia Legislativa de Minas Gerais. Municípios de Minas. Disponível em $<\mathrm{http}$ ://www. almg.gov.br/consulte/info_sobre_minas $>$. Acesso em 17 Abr 2012.

Alves, R.J.V. \& Kolbek, J. 2009. Summit vascular flora of Serra de São José, Minas Gerais, Brazil. Check list 5: 35-73.

Alves, R.J.V. \& Kolbek, J. 2010. Can campo rupestre vegetation be floristically delimited based on vascular plant genera? Plant Ecology 207: 67-79.
Alves, R.J.V; Cardin, L. \& Kropf, M.S. 2007. Angiosperm disjucntion "Campos rupestres-restingas": a reevaluation. Acta Botanica Brasilica 21: 675-685.

Arbo, M.M. \& Giulietti, A.M. 2009. Turneraceae. In: Giulietti, A.M.; Rapini, A.; Andrade, M.J.G; Queiroz, L.P. \& Silva, J.M.C. (org.). 2009. Plantas raras do Brasil. Conservation International, Belo Horizonte. 496p.

Atkins, S. 2005. The genus Stachytarpheta (Verbenaceae) in Brazil. Kew Bulletin 60:161-272.

Azevedo, C.O. \& van den Berg, C. 2007. A família Orchidaceae no Parque Municipal de Mucugê, Bahia, Brasil. Hoehnea 34: 1-47.

Baltazar, O.F.; Baars F.J.; Lobato, L.M.; Reis, L.B.; Achtschin, A.B.; Berni, G.V. \& Silveira, V.D. 2005. Mapa geológico do Quadrilátero Ferrífero na escala 1:50.000 com nota explicativa. In: Projeto Geologia do Quadrilátero Ferrífero - Integração e Correção Cartográfica em SIG com Nota Explicativa. CODEMIG, Belo Horizonte. DVD.

Bertrand, G. 1972. Paisagem e geografia física global: esboço metodológico. Caderno de Ciências da Terra 13: 1-27.

Borges, R.A.X.; Saavedra, M.M. \& Nakajima, J.N. 2010. The Asteraceae flora of the Serra do Ibitipoca: analyses of its diversity and distribution compared with selected areas in Brazilian mountain. Systematic and Biodiversity 8: 471-479.

Bussel, J.D. \& James, S.H. 1997. Rocks as museums of evolutionary processes. Journal of the Royal Society of Western Australia 80: 221-229.

Caiafa, A.N. \& Silva, A.F. 2005. Composição florística e espectro biológico de um campo de altitude no Parque Estadual da Serra do Brigadeiro, Minas Gerais, Brasil. Rodriguésia 56: 163-173.

Carmo, F.F., Carmo, F.F., Salgado, A.A.R. \& Jacobi, C.M. 2011. Novo sítio espeleológico em sistemas ferruginosos no Vale do Rio Peixe Bravo, Norte de Minas Gerais, Brasil. Espeleo-Tema 22: 79-93.

Carmo, F.F. \& Jacobi, C.M. 2012. As cangas do Quadrilátero Ferrífero. In: Jacobi, C.M. \& Carmo, F.F. (orgs.). Diversidade florística nas cangas do Quadrilátero Ferrífero. Ed. IDM, Belo Horizonte. Pp. 1-13.

Carmo, F.F.; Carmo, F.F.; Campos, I.C. \& Jacobi, C.M. 2012. Cangas: ilhas de ferro estratégicas para a conservação. Ciência Hoje 295: 48-53.

Castro, P.T.A. 2008. Cangas: a influência da geodiversidade na biodiversidade. In: Simpósio Afloramentos Ferruginosos no Quadrilátero Ferrífero: Biodiversidade, Conservação e Perspectivas de Sustentabilidade. Belo Horizonte. Pp. 30-51.

Conceição, A.A. \& Pirani, J.R. 2005. Delimitação de habitats em campos rupestres na Chapada Diamantina, Bahia: substrato, composição florística e aspectos estruturais. Boletim de Botânica da Universidade de São Paulo 23: 85-111. 
Costa, F.N.; Trovó, M. \& Sano, P.T. 2008. Eriocaulaceae na Cadeia do Espinhaço: riqueza, endemismo e ameaças. Megadiversidade 4: 117-125.

Dematteis, M. \& Angulo, M.B. 2010. Additions to the genus Lessingianthus (Asteraceae, Vernonieae) from South America. Rodriguésia 61: 233-241.

Dinerstein, E.; G.J. Schipper \& D.M. Olson. 1995. A conservation assessment of the terrestrial ecoregions of Latin America and the Caribbean. WWF, Washington DC. 177p.

Dorr II, J. v. N. 1969. Physiographic, stratigraphic and structural development of Quadrilátero Ferrífero, Minas Gerais, Brazil. United States Geological Survey. Prof. Paper, 641-A. Washington. 110p.

Dutra, V.F.; Garcia, F.C.P.; Lima, H.C. \& Queiroz, L.P. 2008. Diversidade florística de Leguminosae Adans. em áreas de campos rupestres. Megadiversidade 4: 117-125.

Echternacht, L.; Trovó, M. \& Sano, P.K. 2012. Eriocaulaceae. In: Jacobi, C.M. \& Carmo, F.F. (orgs.). Diversidade florística nas cangas do Quadrilátero Ferrífero. Ed. IDM, Belo Horizonte. Pp. 114-119.

Ferreira, R.L. 2005. A vida subterrânea nos campos ferruginosos. O Carste 3: 106-115.

Ferreira, S.C. 2012. Agrianthus. In: Forzza, R.C. et al. (eds.). Lista de espécies da flora do Brasil. Jardim Botânico do Rio de Janeiro. Disponível em $<$ http:// floradobrasil.jbrj.gov.br/2012/FB015937>. Acesso em 20 Mai 2012.

Ferrero, R. \& Mello-Silva, R. 2011. Droseraceae do Parque Estadual do Ibitipoca, Minas Gerais, Brasil. Boletim de Botânica da Universidade de São Paulo 29: 13-18.

Forzza, R.C. et al. 2012. Lista de Espécies da Flora do Brasil. Disponível em $<$ http://reflora.jbrj. gov.br/jabot/listaBrasil/ConsultaPublicaUC/ ConsultaPublicaUC.do>. Acessos em 10 Jan 2012 e 26 Mar 2013.

Fundação SOS Mata Atlântica. 2011. Atlas dos Remanescentes Florestais da Mata Atlântica Período 2008-2010. 122 p. Disponível em <http://www. sosma.org.br/projeto/atlas-da-mata-atlantica $>$. Acesso em 22 Dez 2012.

Garcia, R.J.F.; Longhi-Wagner, H.M.; Pirani, J.R. \& Meirelles, S.T. 2009. A contribution to the phytogeography of Brazilian campos: an analysis based on Poaceae. Revista Brasileira de Botânica 32: 703-713.

Gibson, N.; Yates, C.J. \& Dillon, R. 2010. Plant communities of the ironstone ranges of South Western Australia: hotspots for plant diversity and mineral deposits. Biodiversity and Conservation 19: 3951-3962.

Giulietti, A.M.; Menezes, N.L; Pirani, J.R.; Meguro, M. \& Wanderley, M.G.L. 1987. Flora da Serra do Cipó, Minas Gerais: caracterização e lista de espécies. Boletim de Botânica da Universidade de São Paulo 9: 1-151.

Giulietti, A.M. \& Forero, E. 1990. Diversidade taxonômica e padrões de distribuição das angiospermas brasileiras. Introdução. Acta Botanica Brasilica 4: 3-10.

Giulietti, A.M. \& Hensold, N. 1990. Padrões de distribuição geográfica dos gêneros de Eriocaulaceae. Acta Botanica Brasilica 4: 133-158.

Giulietti, A.M.; Pirani J.R. \& Harley, R.M. 1997. Espinhaço Range Region, Eastern Brazil, Site SA20. Centres of plant diversity: South America. Disponível em <http://botany.si.edu/projects/cpd/ sa/sa20.htm>. Acesso em 10 Jan 2012.

Giulietti, A.M.; Rapini, A.; Andrade, M.J.G; Queiroz, L.P. \& Silva, J.M.C. (orgs.). 2009. Plantas raras do Brasil. Conservation International, Belo Horizonte. 496p.

Goldenberg, R.; Baumgratz, J.F.A. \& M.L. Souza. 2012. Taxonomia de Melastomataceae no Brasil: retrospectiva, perspectivas e chave de identificação para os gêneros. Rodriguésia 63: 145-161.

Hammer, Ø.; Harper, D.A.T. \& P. D. Ryan, 2001. PAST: Paleontological statistics software package for education and data analysis. Palaeontologia Electronica 4: 1-9.

Harley, R.M. 1995. Introdução. In: Stannard, B.L. (ed.). Flora of Pico das Almas, Chapada Diamantina, Bahia, Brazil. Royal Botanic Gardens, Kew. 853p.

Harley, R.M. 1996. The Labiatae of Bahia: a preliminary check-list. Sitientibus 15:11-21.

Heiden, G; Iganci, J.R.V.; Bobrowski, V.L. \& Macias, L. 2010. Biogeografia de Baccharis sect. Caulopterae (Asteraceae) no Rio Grande do Sul, Brasil. Rodriguésia 58: 787-796.

Jacobi, C.M.; Carmo, F.F.; Vincent, R.C. \& Stehmann, J.R. 2007. Plant communities on ironstone outcrops - a diverse and endangered Brazilian ecosystem. Biodiversity and Conservation 16: 2185-2200.

Jacobi, C.M. \& Carmo, F.F. 2008a. Diversidade dos campos rupestres ferruginosos no Quadrilátero Ferrífero, MG. Megadiversidade 4: 24-32.

Jacobi, C.M., Carmo, F.F. \& Vincent, R.C. 2008 b. Vegetação sobre canga e seu potencial para reabilitação ambiental no Quadrilátero Ferrífero, MG. Revista Árvore 32: 345-353.

Jacobi, C.M.; Carmo, F.F. \& Campos, I.C. 2011. Soaring extinction threats to endemic plants in brazilian metal-rich regions. AMBIO 40: 540-543.

Jacobi, C.M. \& Carmo, F.F. (orgs.). 2012. Diversidade florística nas Cangas do Quadrilátero Ferrífero. Ed. IDM, Belo Horizonte. 240p.

Jacobi, C.M., Carmo, F.F., Carmo, F.F. \& Campos, I.C. Iron Geosystems: priority areas for conservation in Brazil. In: Tibbett, M. (ed.). Mining in ecologically sensitive 
landscapes. Commonwealth Scientific and Industrial Research Organization, Collingwood. no prelo.

Kruckeberg, A.R. 2004. Geology and plant life: the effects of landforms and rock types on plants. University of Washington Press. 363p.

Mamede, M.C.H. 1990. Revisão do gênero Camarea Saint-Hilaire (Malpighiaceae). Hoehnea 17: 1-34.

Meguro, M.; Pirani, J.R.; Mello-Silva, R. \& Giulietti, A.M. 1996. Estabelecimento de matas ripárias e capões nos ecossistemas campestres da Cadeia do Espinhaço, Minas Gerais. Boletim de Botânica da Universidade de São Paulo 15: 1-11.

Monteiro, D. \& Guimarães, E.F. 2008. Flora do Parque Nacional do Itatiaia - Brasil: Peperomia (Piperaceae). Rodriguésia 59: 161-195.

Mota, R.C.; Batista, J.A.N. \& Borba, E.L. 2012. Orchidaceae. In: Jacobi, C.M. \& Carmo, F.F. (orgs.). Diversidade florística nas cangas do Quadrilátero Ferrífero. Ed. IDM, Belo Horizonte. Pp. 158-162.

Mourão, A. \& Stehmann, J.R. 2007. Levantamento da flora do campo rupestre sobre canga hematítica couraçada remanescente na Mina do Brucutu, Barão de Cocais, Minas Gerais, Brasil. Rodriguésia 58: 775-786.

Oliveira-Filho, A.T. \& Fontes, M.A.L. 2000. Patterns of floristic differentiation among Atlantic Forests in Southeastern Brazil and the influence of climate. Biotropica 32: 793-810.

Oliveira-Filho, A.T.; Tameirão-Neto, E.; Carvalho, W.A.C.; Werneck, M.; Brina, A.E.; Vidal, C.V.; Resende, S.C. \& Pereira, J.A.A. 2005. Análise florística do compartimento arbóreo de áreas de floresta atlântica sensu lato na região das bacias do leste (Bahia, Minas Gerais, Espírito Santo e Rio de Janeiro). Rodriguésia 56: 185-235.

Pereira, I.M.; Oliveira-Filho, A.T.; Botelho, S.A.; Carvalho, W.A.C.; Fontes, M.A.L; Schiavini, I. \& Silva, A.F. 2006. Composição florística do compartimento arbóreo de cinco remanescentes do Maciço do Itatiaia, Minas Gerais e Rio de Janeiro. Rodriguésia 57: 103-126.

Pirani, J.R.; Mello-Silva, R. \& Giulietti, A.M. 2003. Flora de Grão-Mogol, Minas Gerais, Brasil. Boletim de Botânica da Universidade de São Paulo 21: 1-24.

Porto, M.L. \& Silva, M.F.F. 1989. Tipos de vegetação metalófila em áreas de Serra de Carajás e de Minas Gerais. Acta Botanica Brasilica 3: 13-21.

Rando, J.G. \& Pirani, J.R. 2011. Padrões de distribuição geográfica das espécies de Chamaecrista sect. Chamaecrista ser. Coriaceae (Benth.) H. S. Irwin \& Barneby, Leguminosae - Caesalpinioideae. Revista Brasileira de Botânica 34: 499-513.

Rapini, A; Ribeiro, P.L. \& Pirani, J.B. 2008. A flora dos campos rupestres da Cadeia do Espinhaço. Megadiversidade 4: 16-23.
Renger, F.E. 2005. O "Quadro Geognóstico do Brasil" de Wilhelm Ludwig von Eschwege: breves comentários à sua visão da geologia do Brasil. GEONOMOS 13: 91-95.

Ribeiro, K.T. \& Medina, B.M.O. 2002. Estrutura, dinâmica e biogeografia das ilhas de vegetação sobre rocha do Planalto do Itatiaia, RJ. Boletim do Parque Nacional do Itatiaia 10: 1-82.

Ritter, M.R. \& Waechter, J.L. 2004. Biogeografia do gênero Mikania Willd. (Asteraceae) no Rio Grande do Sul, Brasil. Acta Botanica Brasilica 18: 643-652.

Rizzini, C.T. 1979. Tratado de fitogeografia do Brasil. Aspectos sociológicos e florísticos. HUCITEC/ EDUSP, São Paulo. 374 p.

Rodrigues, C. 2001. A Teoria Geossistêmica e sua contribuição aos estudos geográficos e ambientais. Revista do Departamento de Geografia USP 14: 69-77.

Romero, R. 2003. Revisão taxonômica de Microlicia sect. Chaetostomoides (Melastomataceae). Revista Brasileira de Botânica 26: 429-435,

Sakuragui, C.M. 2001. Biogeografia de Philodendron seção Calostigma (Schott) Pfeiffer (Araceae) no Brasil. Acta Scientiarum 23: 561-569.

Scarano, F.R. 2007. Rock outcrop vegetation in Brazil: a brief overview. Revista Brasileira de Botânica 30: 561-568.

Schaefer, C.E.G.R.; Mendonça, B.A.F. \& Ribeiro, A.S. 2008. Solos desenvolvidos sobre canga ferruginosa no Quadrilátero Ferrífero, Minas Gerais. In: Jacobi, C.M. (ed.). Simpósio Afloramentos Ferruginosos no Quadrilátero Ferrífero: Biodiversidade, Conservação e Perspectivas de Sustentabilidade. UFMG/ ICB, Belo Horizonte.

Schobbenhaus C. \& Coelho C.E.S (orgs.). 1986. Principais depósitos minerais do Brasil: ferro e metais da indústria do aço. Vol.2. Departamento Nacional de Produção Mineral, Brasília. 501p.

Semir, J. 1991. Revisão taxonômica de Lychnophora Mart. (Vernoniaceae:Compositae). Tese de Doutorado. Universidade Estadual de Campinas, Campinas. 515p.

Silva, M.F.F. 1992. Distribuição de metais pesados na vegetação metalófila de Carajás. Acta Botanica Brasilica 6: 107-122.

Silva, R.R. \& Tozzi, A.M.G.A. 2011. Uma nova espécie de Mimosa L. (Leguminosae, Mimosoidea) do Centro-Oeste do Brasil. Hoehnea 38: 143-146.

Simão-Bianchini, R. 2012. Convolvulaceae. In: Jacobi, C.M. \& Carmo, F.F. (Orgs.). Diversidade Florística nas Cangas do Quadrilátero Ferrífero. Ed. IDM, Belo Horizonte. Pp. 103-105.

Simon, M.F. \& Proença, C. 2000. Phytogeographic patterns of Mimosa (Mimosoideae, Leguminosae) in the Cerrado biome of Brazil: an indicator genus 
of high-altitude centers of endemism? Biological Conservation 96: 279-296.

Spósito, T.C. \& Stehmann, J.R. 2006. Heterogeneidade florística e estrutural de remanescentes florestais da Área de Proteção Ambiental ao sul da região metropolitana de Belo Horizonte (APA Sul-RMBH), Minas Gerais, Brasil. Acta Botanica Brasilica 20: 347-362.

Stannard, B.L. 1995. (ed.). Flora of Pico das Almas, Chapada Diamantina, Bahia, Brazil. Royal Botanic Gardens, Kew. 853p.

Valente, A.S.M.; Garcia, P.O.; Salimena, F.R.G. \& Oliveira-Filho, A.T. 2011. Composição, estrutura e similaridade florística da Floresta Atlântica na Serra Negra, Rio Preto - MG. Rodriguésia 62: 321-340.

Versieux, L.M. 2011. Brazilian plants urgently needing conservation: the case of Vriesea minarum (Bromeliaceae). Phytotaxa 28: 35-49.

Versieux, L.M. 2012. Bromeliaceae. In: Jacobi, C.M. \& Carmo, F.F. (orgs.). Diversidade florística nas cangas do Quadrilátero Ferrífero. Ed. IDM, Belo Horizonte. Pp. 93-97.

Versieux, L.M. \& Wendt, T. 2007. Bromeliaceae diversity and conservation in Minas Gerais state, Brazil. Biodiversity and Conservation 16: 2989-3009.
Versieux, L.M.; Wendt, T.; Louzada, R.B. \& Wanderley, M.G.L. 2008. Bromeliaceae da Cadeia do Espinhaço. Megadiversidade 4: 98-110.

Viana, P.L. \& J.A. Lombardi. 2007. Florística e caracterização dos campos rupestres sobre canga na Serra da Calçada, Minas Gerais, Brasil. Rodriguésia 58: 159-177.

Viana, P.L. \& Filgueiras, T.S. 2008. Inventário e distribuição geográfica das gramíneas (Poaceae) na Cadeia do Espinhaço, Brasil. Megadiversidade 4: 71-88.

Vincent, R.C. \& Meguro, M. 2008. Influence of soil properties on the abundance of plant species in ferruginous rocky soils vegetation, southeastern Brazil. Revista Brasileira de Botânica 31: 377-388.

Whiting, S.N.; Reeves, R.D. \& Baker, A.J.M. 2002. Conserving biodiversity: mining metallophytes and land reclamation. Mining Environmental Management 10: 11-16.

Zappi, D.C.; Lucas, E.; Stannard, B.L.; Lughadha, E.N.; Pirani, J.R.; Queiroz, L.P.; Atkins, S.; Hind, D.J.N.; Giulietti, A.M.; Harley, R.M. \& Carvalho, A.M. 2003. Lista das plantas vasculares de Catolés, Chapada Diamantina, Bahia, Brasil. Boletim de Botânica da Universidade de São Paulo 21: 345-398. 